\title{
Incidence of dysmenorrhoea associated with high stress scores among the undergraduate Nepalese medical students
}

\author{
T. Pramanik, R. Shrestha, M.T. Sherpa, P. Adhikari \\ Department of Physiology, Nepal Medical College. Healthy Human Society, Jorpati, Kathmandu, Nepal.
}

Correspondence to: Dr. Prakash Adhikari, Healthy Human Society, Jorpati, Kathmandu, Nepal.

Email: healthy_hs@hotmail.com

\begin{abstract}
Introduction: Primary dysmenorrhoea is one of the major problems associated with menstruation among the young undergraduate medical students which affect their daily routine. Among various causes, mental stress is one of the major causes of primary dysmenorrhoea. This study aims to assess the relationship between the degree of stress and incidence of dysmenorrhoea amongst the young Nepalese medical students.

Methods: Young, unmarried, non-smoker female medical undergraduate students (age: 18-20years, $\mathrm{n}$ $=104$ ) having no pelvic pathology participated in this study. A baseline questionnaire was used to note the medical history on menstruation, use of contraceptive pills, active or passive smoking exposure and alcohol use. The independent and individual perception of stress was evaluated by using a stress questionnaire.

Results: Result indicated that the stress score is significantly higher (31.30 vs. 18.81) in dysmenorrhoeic women $(n=50)$ compared to eumenorrhoeic participants $(n=54)$.

Conclusions: The present study indicated a positive relationship between psychological stress (supported by stress scores) and dysmenorrhoea. The path of solution of this painful problem might be paved out by de-stressing the person through relaxation exercise, yoga and pranayama (the breathing exercises.)
\end{abstract}

Keywords: Primary dysmenorrhoea, psychological stress, yoga.

\section{Introduction}

Dysmenorrhoea (pain during menstruation) affects 40-95\% of menstruating women, and has been reported as the most common cause of regular absenteeism among young women. ${ }^{1,2}$ Dysmenorrhoea in adolescents is usually primary, and is associated with normal ovulatory cycles and with no pelvic pathology whereas secondary dysmenorrhoea is painful menstruation that is frequently associated with a pelvic pathology. Risk factors for primary dysmenorrhoea include nulliparity, heavy menstrual flow, smoking, poor mental health and social support and young age.,3,4,6
Amongst the battery of causes, mental stress is one of the major risk factors of dysmenorrhoea.$^{7,8}$ Depression and anxiety are strongly associated with menstrual pain. ${ }^{9,10}$ The reports of the incidence of stress induced dysmenorrhoea in Nepalese medical students are scanty, although to the best of our knowledge a good number of young unmarried female undergraduate medical students used to suffer from this problem; those are constantly under pressure of studies and are deprived of psychological support and counseling, living in hostels away from their homes. This study is done to assess the relationship between the degree of stress (evaluated by stress score) and incidence of dysmenorrhoea 
Incidence of dysmenorrhoea

amongst the young Nepalese medical students.

\section{Methods}

Young, unmarried, non-smoker female undergraduate medical students (age 18-20yrs, $\mathrm{n}=104$ ) having no known pelvic pathology (as suggested by history and examination) were included in this study. A baseline questionnaire was used to note the medical history on menstruation, use of contraceptive pills, active or passive smoking exposure and alcohol use. Female students who were married or those who were suspected of having pelvic pathology were excluded from the study after being examined by a Gynecologist. The independent and individual perception of stress was evaluated by using a stress questionnaire. ${ }^{10}$ The questionnaire contained 20 statements (e.g., I am able to speak openly about my feeling when angry or worried) and the volunteer had to score each item from 1 (almost always) to 5 (never) according to how much of the time each statement applied to her. Five different grades were: almost always (1), often (2), sometimes (3), rarely (4) and never (5). Hence, one could score maximum 100 in a questionnaire. Stress score was derived subtracting 20 from the total score. If the score was above 30 , person was considered as vulnerable to stress.

It was a prospective study conducted between January 2009 and May 2009 at Nepal Medical College. All females of above mentioned age group were included in the study. Females using contraceptive pills, consuming alcohol and who were smokers were excluded. The stress scores and the menstrual history (i.e. either normal or experienced dysmenorrhoea) of individual participants were compared by using student ' $t$ ' test.

\section{Results}

The stress score derived from the volunteers who used to suffer from dysmenorrhoea was significantly high (31.30) in comparison to the scores derived from the participants having no complaints (18.81) of dysmenorrhoea (Table 1, Fig. 1)

Table 1: Stress scores among the eumenorrhoeic and dysmenorrhoeic women

$\begin{array}{lc}\text { Participants } & \begin{array}{l}\text { Stress Score } \\ (\text { Mean } \pm \text { SD) }\end{array} \\ \begin{array}{l}\text { Participants Experienced } \\ \text { dysmenorrhoea }(n=50)\end{array} & 31.30 \pm 1.87^{*} \\ \begin{array}{l}\text { Participants with normal } \\ \text { menstruation }(\mathrm{n}=54)\end{array} & 18.81 \pm 4.33\end{array}$

$*=p>0.05$

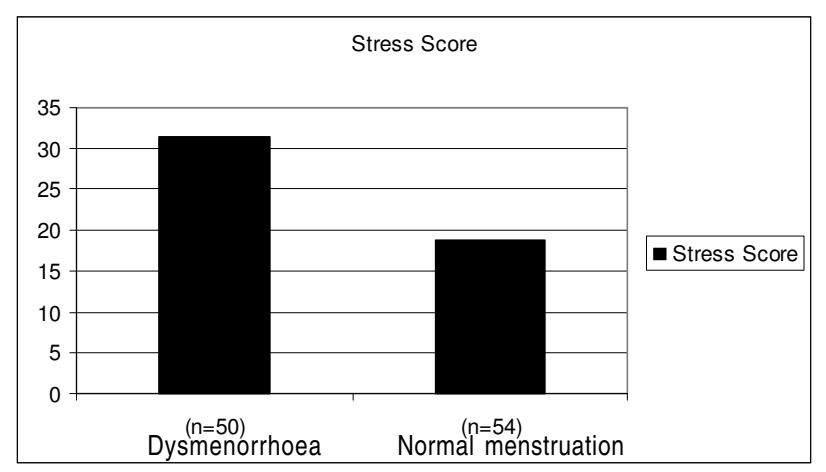

Fig. 1: Stress score in patients with dysmenorrhoea and normal menstruation

\section{Discussion}

Dysmenorrhoea is one of the most distressing problems associated with menstruation among the undergraduate medical students which affects the daily routine. It causes prolonged resting hours and inability to study. ${ }^{11}$ Results of the present study indicated clear positive relation between stress score and dysmenorrhoea. This result corroborates the result of previous studies worked out. ${ }^{12}$ Compared to women with low stress the risk of dysmenorrhoea was $60 \%$ greater among the women with moderate stress and more than twice as great among those with high stress. ${ }^{7}$ Study among US Air Force employees also showed that high stress was associated with more than two fold increase in risk for dysmenorrhoea. ${ }^{8}$

Potent prostaglandins and potent leukotrienes play an important role in generating dysmenorrhoea symptoms. ${ }^{13}$ Prostaglandin F2á and Prostaglandin E2 which are secreted from the secretory endothelium bind to myometrial receptors and increase the tone of myometrium and sensitivity of myometrium to prostaglandin. Prostaglandin, a strong vasoconstrictor causes vasoconstriction of uterine vessels leading to ischemia of myometrium (myometrial angina) and pain.

Progesterone affects the synthesis of prostaglandin F2á and binding of it to myometrial receptor. ${ }^{14,15}$ Intracellular administration of progesterone results in decreased biosynthesis of prostaglandin F2á ${ }^{16}$ The concentration of progesterone per menstruation was significantly higher in eumenorrhoeic women than in the dysmenorrhoeic patients and menstrual excretion of prostaglandin F2á was 2.5 times higher in dysmenorrhoeic women compared to normal participants. ${ }^{17}$

Stress, inhibits the pulsatile release of follicle stimulating hormone (FSH) and luteinizing hormone (LH) leading to impaired follicular development. ${ }^{18}$ As synthesis of 
progesterone is increased in the leuteinized follicle following ovulation, stress induced impairment of follicular development could potentially reduce progesterone synthesis and release. Reduced progesterone may cause increased production of prostaglandin, the mediator of pain. On the top of it, reduced titer of progesterone caused increased myometrial contraction, that gives more strain to ischemic myometrium and intensify pain resulting dysmenorrhoea.

\section{Conclusions}

The present study indicated a positive relationship between psychological stress (supported by stress scores) and dysmenorrhoea. The path of solution of this painful problem might be paved out by de-stressing the person through relaxation exercise, yoga and pranayama (the breathing exercises.)

\section{Acknowledgements}

Authors are thankful to Dr. S.B. Rizyal, Principal, Nepal Medical College, Dr Paresh Roychowdhury, HOD, Department of Physiology and all the faculties and staffs of Physiology Department. Authors are also thankful to 'Binay Tara Foundation' for financial support.

\section{References}

1. Jones AE. Managing the pain of primary and secondary dysmenorrhoea. Nurs

Times. 2004;100:40-3.

1. Ng TP, Tan NC, Wansaicheong GK. A prevalence study of dysmenorrhoea in female residents aged 15-54 years in Cleminti town, Singapore. Ann Acad Med Singapore. 1992;21(3):323-7.

2. Harel Z. Dysmenorrhoea in adolescents. Ann N Y Acad Sci. 2008;1135:185-95.

3. Pullson S, Reinken J, Sparrow M. Prevalence of dysmenorrhoea in Wellington Women. NZ Med J. 1988;101:52-4.

4. Burnett MA, Antao V, Black A, et al. Prevalence of primary dysmenorrhoea in Canada. J Obstet Gynaecol Can. 2005;27:765-70.

5. French L. Dysmenorrhoea in adolescents: diagnosis and treatment. Paediatr Drugs. 2008;10:1-7.

6. Christiani DC, Niu T, Xu X. Occupational stress and dysmenorrhoea in women working in cotton textile mills. Int J Occup Environ Health. 1995;1:9-15.
7. Gordley LB, Lemasters G, Simpson SR, et al. Menstrual disorder and occupational, stress and racial factors among military personnel. J Occup Environ Med. 2000;42:871-81.

8. Alonso C, Coe CL. Disraptions of social relationships accentuate the association between emotional distress and menstrual pain in young women. Health Psychol 2001;20:411-6.

9. Gunel MK, Akkaya FY. Are migraineur women really more vulnerable to stress and less able to cope: BMC Health Service Res. 2008;8:211.

10. Sharma A, Taneja DK, Sharma P, Saha R. Problems related to menstruation and their effect on daily routine of students of a medical college in Delhi, India. Asia-Pacific J Public Health. 2008;20:234-41.

11. Wang, Wang X, Wang W, et al. Stress and dysmenorrhoea: A population based prospective study. Occup Environ Med. 2004;61:1021-6.

12. Harel Z. Dysmenorrhoea in adolescents and young adults: etiology and management. J. Pediatr Adol Gynaecol. 2006;19:363-71.

13. Friederich MA. Dysmenorrhoea. Women Health. 1983;8:91-106.

14. Ylikorkala O, Dawood MY. New Concept in dysmenorrhoea, Am J Obstet Gynecol. 1978;130:83347.

15. Trobough G, Guderian AM, Erickson RR, et al. The effect of exogenous intrauterine progesterone on the amount and prostaglandin F2 alpha content of menstrual blood in dysmenorrheic women. J Reprod Med. 1978;21:153-8.

16. Zahradnik HP, Breckwoldf M. Contribution to the pathogenesis of Dysmenorrhoea. Arch Gynaecol Obstetr. 1984;236:99-108.

17. Chatterton RT. The role of stress in female reproduction: animal and human considerations. Int $\mathbf{J}$ Fertil. 1990;35:8-13. 